\title{
Treatment of Patients with Degenerative Diseases of the Lumbosacral Spine Using a Novel Technology of Facet Stabilization with Facet Wedge Implant
}

DOI: 10.17691/stm2017.9.2.16

Received August 1, 2016

A.A. Kalinin, MD, PhD, Associate Professor, Neurosurgery Course ${ }^{1 ;}$ Neurosurgeon, Neurosurgery Center 2 ;

A.K. Okoneshnikova, Resident Physician, Neurosurgery Course';

V.A. Byvaltsev, MD, DSc, Professor, Head of Neurosurgery Course ${ }^{1}$; Head of Neurosurgery Center2; Head of Clinical Research Department of Neurosurgery3; Professor, Department of Traumatology, Orthopedics and Neurosurgery ${ }^{4}$

${ }^{1}$ Irkutsk State Medical University, 1 Krasnogo Vosstaniya St., Irkutsk, 664003, Russian Federation; ${ }^{2}$ Railway Clinical Hospital, Irkutsk-Passenger Station, Joint Stock Company "Russian Railways", 10 Botkina St., Irkutsk, 664005, Russian Federation;

${ }^{3}$ Irkutsk Scientific Centre of Surgery and Traumatology, 1 Bortsov Revolutsii St., Irkutsk, 664003,

Russian Federation;

${ }^{4}$ Irkutsk State Medical Academy of Postgraduate Education, 100 Yubileiny Microdistrict, Irkutsk, 664079,

Russian Federation

Transpedicular fixation with interbody fusion widely used in management of degenerative diseases of the lumbosacral spine is associated with significant intraoperative aggression during surgery and postsurgical pain syndrome. To improve treatment results, a novel minimally invasive technology of facet fixation with Facet Wedge implant in combination with transpedicular stabilization and interbody fusion has been introduced.

The aim of the investigation was to evaluate the efficacy of facet fixation technology with Facet Wedge implant in combination with transpedicular stabilization and interbody fusion in treatment of patients with degenerative diseases of the lumbosacral spine.

Materials and Methods. The study involved 19 patients who underwent unilateral decompression with transforaminal lumbar interbody fusion, ipsilateral transpedicular stabilization and facet fixation on the contralateral side, according to clinical and instrumental indications. The minimum follow-up period of observation and complex evaluation of treatment results was 12 months.

Results. When assessing pain syndrome by visual analogue scale and the degree of disability according to Oswestry disability index in the early postoperative period and in the long-term period, mostly good and excellent outcomes, statistically significantly better results were observed compared to the preoperative values. An interbody bone block was formed within 12 months in $89 \%$ ( $n=17)$ of patients, according to radiographic data.

Conclusion. Decompression with a novel minimally invasive technology of combined dorsal fusion provides the possibility to significantly reduce pain, lower the degree of disability and implement efficient stabilization of the operated functional spinal segment in patients with degenerative diseases of the lumbosacral spine.

Key words: stabilization of facet joints; transpedicular fixation; spinal canal decompression; lumbosacral spine; degenerative lesion of the intervertebral disc; TLIF.

Many degenerative diseases of the lumbosacral spine are the indication for performing interbody fusion $[1,2]$. Transpedicular fixation of interbody cages has been the gold standard in effective stabilization of vertebral motion segments after resection of posterior supporting elements for decompression of spinal canal structures [3, 4].

The method of transforaminal lumbar interbody fusion (TLIF), first introduced by Harms and Rolinger in 1982 [5], has gained popularity in the last two decades. The advantages of transforaminal interventions over the classical posterior interbody fusion have been confirmed by a number of studies: low risks of damage to dura mater and the spinal roots, lower blood loss, better bone block formation [6, 7]. However, some authors evidence the significant injury of paravertebral tissues and muscular-ligamentous apparatus resulting from such interventions and contributing to the formation of rough scar-adhesion changes accompanied by durable postoperative pain and reduced life quality [8-11].

Search for technological solutions improving the results of decompression/stabilization interventions

For contacts: Vadim A. Byvaltsev, e-mail: byval75vadim@yandex.ru 
in patients with degenerative segmental instability of the lumbosacral spine is intended to minimize surgical aggression while maintaining the efficacy of the operated segment fixation. To achieve this, the method of translaminar facet fixation with two screws inserted in the vertebral arch through the base of the spinous process, developed by Magerl in 1984 [12], has been used as an alternative to transpedicular fixation.

Many studies have confirmed lower incidence of surgical trauma with translaminar facet fixation compared to transpedicular stabilization, yet the data about biomechanical recovery of the operated spinal region and the timescales of reliable bone block formation are rather contradictory [13-15].

In modern literature, the authors have found no clinical research information on the use of facet fixation with Facet Wedge implant in treatment of patients with degenerative diseases of the lumbosacral spine, which has become the subject of the present study.

The aim of the investigation was to evaluate the efficacy of facet fixation technology with Facet Wedge implant in combination with transpedicular stabilization and interbody fusion in treatment of patients with degenerative diseases of the lumbosacral spine.

Materials and Methods. The prospective nonrandomized cohort study involved 19 patients (13 males, 6 females) aged 39 (30-46) years, who underwent treatment at the Neurosurgery Center of Railway Clinical Hospital, Irkutsk-Passenger Station, Joint Stock Company "Russian Railways", during the period from January 2015 to September 2016. In the pre-operative period, the patients' past history, complaints, neurological status were evaluated. All the patients underwent standard conservative treatment for 6-8 weeks before surgery, which appeared to be ineffective.

Surgical intervention and direct decompression of the neural structures were performed according to standard procedures generally accepted in neurosurgery, using optical magnification, specialized instrumentation and specific retraction systems for minimally invasive surgery.

The indications for discectomy via transforaminal approach followed by instrumental fixation were as follows:

ineffective conservative therapy, prolonged or recurrent pain syndrome, permanent neurological deficit (that range from radiculoneuralgia to radiculopathy with peripheral nerve palsy);

herniation of the intervertebral discs followed by disc space and spinal canal narrowing that caused the corresponding clinical symptoms (organic substrate of neural structure compression), according to neuroimaging data;

segmental instability signs (linear translation in the segment by more than $4 \mathrm{~mm}$, sagittal angulation of more than $15^{\circ}$ ), based on the results of functional radiography of the spine.
Severe comorbidity served as a contraindication for decompression/stabilization interventions.

Inclusion criterion in treating degenerative diseases of the lumbosacral spine by facet fixation was the need for stabilization of posterior support complex in order to form vertebral fusion. Exclusions for application of a facet cage were revisional decompression/stabilization interventions, the presence of radiological signs of spondylolisthesis, significant reduction of mineral density of the bone tissue (osteoporosis) as well as marked changes or grade IV degeneration of facet joint structure according to Fujiwara [16]. Surgical interventions were performed on one vertebral motion segment in all cases: $\mathrm{L}_{\mid I I}-\mathrm{L}_{\mid \mathrm{V}}-3$ persons; $\mathrm{L}_{\mathrm{IV}}-\mathrm{L}_{\mathrm{V}}-8$ persons; $\mathrm{L}_{V}-\mathrm{L}_{\mathrm{VI}}-$ 4 persons; $L_{V}-S_{1}-4$ persons.

All the patients were operated on by the same surgical team.

Surgery was performed under intravenous anesthesia with artificial lung ventilation, with the patient positioned on a set of bolsters in a prone position. A paramedian approach was performed in projection of coupled joints of symptom-oriented vertebral motion segment under C-arm fluoroscopy guidance (Philips, Netherlands). Facetectomy with decompression of the spinal canal structure, discectomy, foraminotomy and meningoradiculolysis was performed via Wiltse posterolateral approach [17] using Insight wound retractor (Synthes, Switzerland) and optical magnification (Pentero 900 microscope; Carl Zeiss Meditec AG, Germany). Placement of transforaminal interbody T-pal cage (Synthes, Switzerland) was performed followed by ipsilateral transcutaneous transpedicular fixation with polyaxial cannulated screws, a longitudinal bar and Viper II nuts (Synthes, Switzerland) through the same access without its dilatation. The surgical wound was closed in layers using anesthetics and powdered antibiotics.

On performing X-ray control, a projection incision to the facet joint was made at the same level on the contralateral side using Caspar retractor (Ulrich, Germany). A guide wire inserted and the implant bed was formed. Titanium Facet Wedge cage (Synthes, Switzerland) was placed using the guide wire and fixed with two screws to the adjacent articular processes. The wound was closed according to the technology described above.

After surgery, the minimum follow-up period amounted to 12 months and the maximum follow-up was 16 months (the median of 14 months).

The following intraoperative parameters of surgical interventions and specificity of postoperative management were studied in all the patients: surgery duration, blood loss, length of hospital stay, patient activation time. Clinical efficacy was evaluated relying on pain severity assessment results according to visual analogue scale (VAS) [18], the degree of disability associated with back pain problem according to Oswestry disability index (ODI) [18], satisfaction with the 
surgical treatment results according to Macnab scale [19] and the presence of complications. The parameter values were analyzed before surgery, on discharge and during follow-up examinations recommended 3,6 and 12 months after the intervention. Anterior-posterior and lateral radiographs of the spine and neuroimaging data (magnetic resonance imaging with 1.5 TI Siemens Magnetom Essenza scanner, Germany, multislice spiral computed tomography using Bright Speed Edge (4 spirals), General Electric, USA) were studied to evaluate the reliability of bone block formation.

The study complies with the Declaration of Helsinki (the Declaration was passed in June 1964, Helsinki, Finland and revised in October 2000, Edinburgh, Scotland) and was performed following approval by the Ethic Committee of Irkutsk Scientific Centre of Surgery and Traumatology. Written informed consent was obtained from every patient.

Statistical data processing was performed using Microsoft Excel and Statistica 8.0. To assess the significance of differences in samples, criteria for nonparametric statistics were used (the Wilcoxon test (W) for dependent samples), the level of $p<0.05$ was considered to be the lower confidence level. Statistical significance of differences was determined for repeated measurements (3, 6 and 12 months after surgery) with allowance for the Bonferroni correction $(p<2.5 \%)$. The data are presented in median and interquartile range as Me $[25 ; 75]$.

Results. When analyzing surgery results, the following data were obtained: surgery duration amounted to 90-175 min (median - $150 \mathrm{~min}$ ), blood loss was 65-150 $\mathrm{ml}$ (median - $90 \mathrm{ml}$ ), the patients were activated on the following day after surgery, hospital stay after the operation varied ranging from 9 to 11 days (median - 10).

A significant decrease in pain intensity in both the lumbosacral spine and the lower limbs was observed in all patients after surgery. Pain severity assessment according to VAS (using a section of a $100 \mathrm{~mm}$ line, where score of " 0 " is no pain) revealed positive changes such as a significant decrease in pain severity after spinal surgery from $68[64 ; 78]$ to $24[23 ; 26] \mathrm{mm}$ on discharge $\left(p_{w}=0.0001\right)$ and to $6[4 ; 8] \mathrm{mm}$ in the longterm postoperative period $\left(p_{w}=0.0002\right)$, as well as in the lower limbs - from $82[78 ; 85]$ to $15[14 ; 16] \mathrm{mm}$ in the early postoperative period (on discharge) $\left(p_{w}=0.0001\right)$ and to 3 [2; 4] mm 12 months after surgery $\left(p_{w}=0.0005\right)$ (Figure 1).

Evaluation of life quality in patients according to ODI revealed positive changes in the functional state after surgery: up to $22[20 ; 24]$ on discharge $\left(p_{w}=0.0001\right)$ and $8[8 ; 10]$ in the long-term postoperative period $\left(p_{w}=0.0002\right)$ compared to $74[66 ; 78]$ before the surgery (Figure 2).

When patients provided subjective evaluation of surgical treatment results according to Macnab scale 12 months after the operation, predominantly excellent $(53 \%)$ and good (42\%) postoperative outcomes were observed (Figure 3), no unsatisfactory outcomes noticed.

A postoperative complication associated with a local inflammatory process in addition to intermuscular hematoma was identified in the area of the postoperative wound. A course of antibiotic therapy contributed

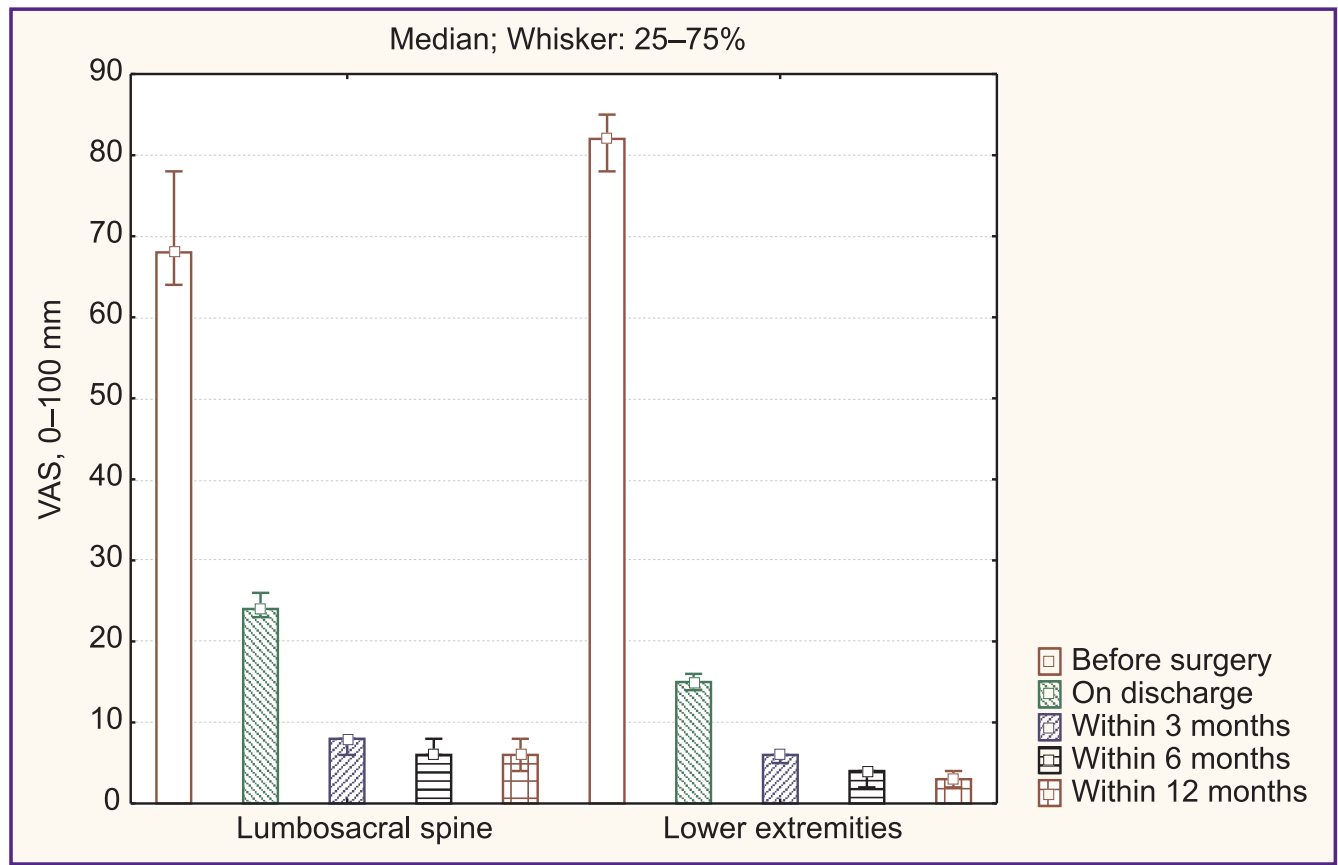

Figure 1. Dynamics of pain level in the lumbosacral spine and the lower extremities of patients under study according to VAS 


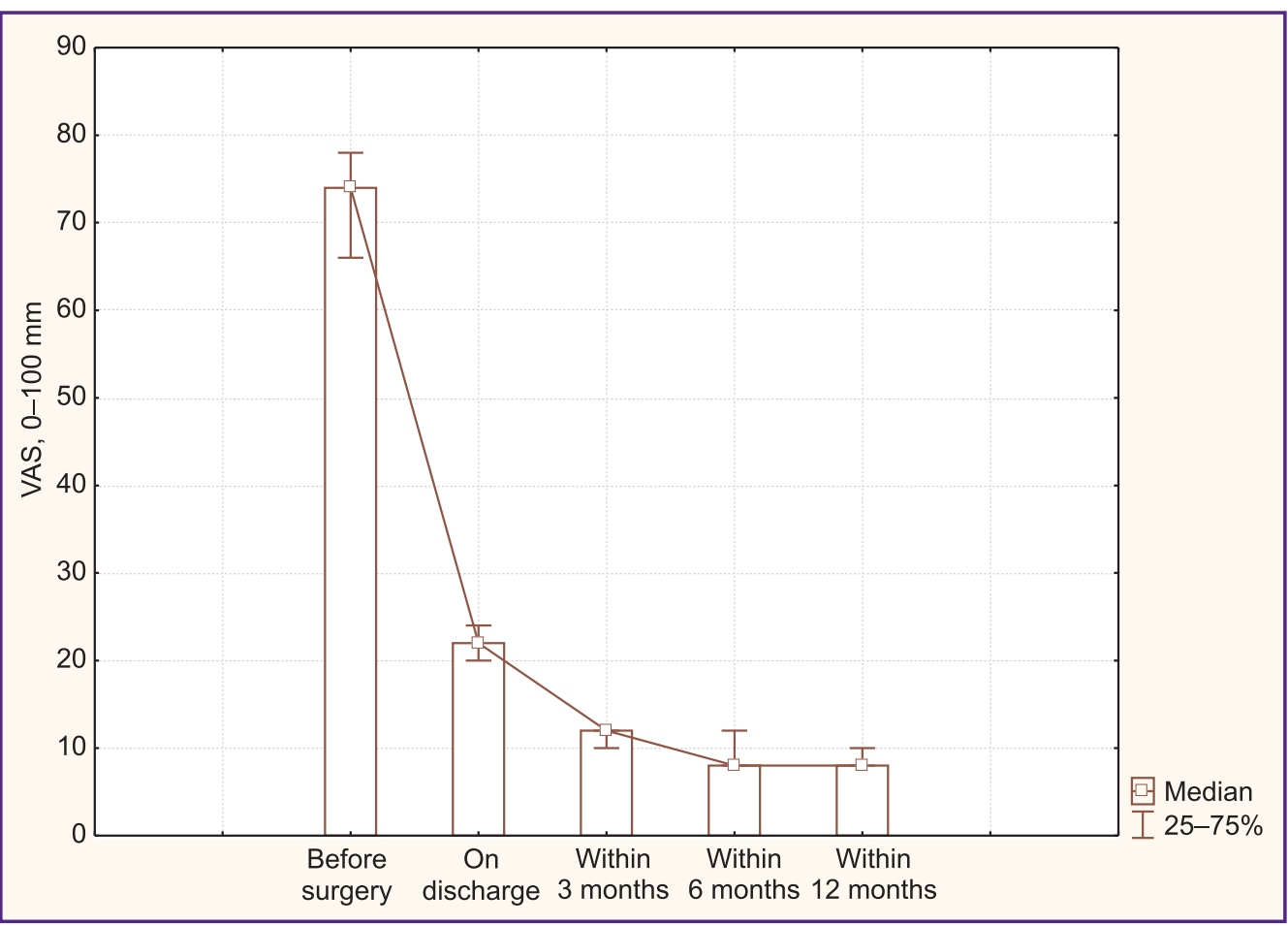

Figure 2. Dynamics of the disability degree in patients under study according to ODI

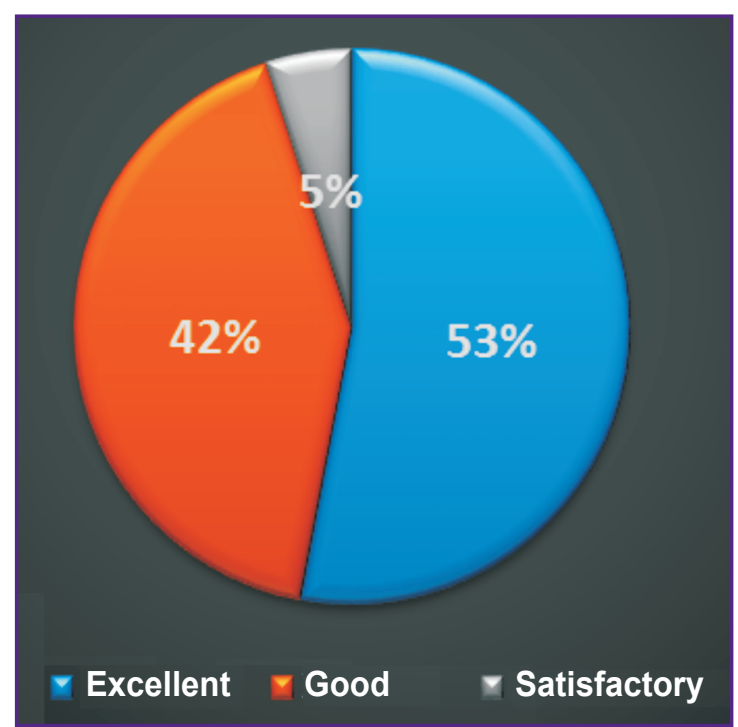

Figure 3. Subjective satisfaction with the operation results in patients under study 12 months after surgery according to Macnab scale

to successful healing of the surgical wound without increasing the period of hospital stay.

All patients showed steady regression of neurological and movement disorders after surgery.

During follow-up (mean time of 12 months), control X-ray pictures of the spine in patients of the group under study revealed no dislocation and migration of an implant, as well as no signs of segmental instability.

No data about the additional compression of neural structures was obtained by magnetic resonance imaging and multislice spiral computed tomography of the lumbosacral spine during follow-up examinations after surgery. Radiographic signs of reliable interbody bone block formation were observed in 17 patients (89\%) who underwent control examination.

Professional rehabilitation analysis showed that 16 patients $(84 \%)$ returned back to their previous jobs 2 months after surgery, 3 persons (16\%) moved to easier jobs and returned to their normal lifestyle 6 months after surgery.

Figure 4 provides an example of instrumental data 

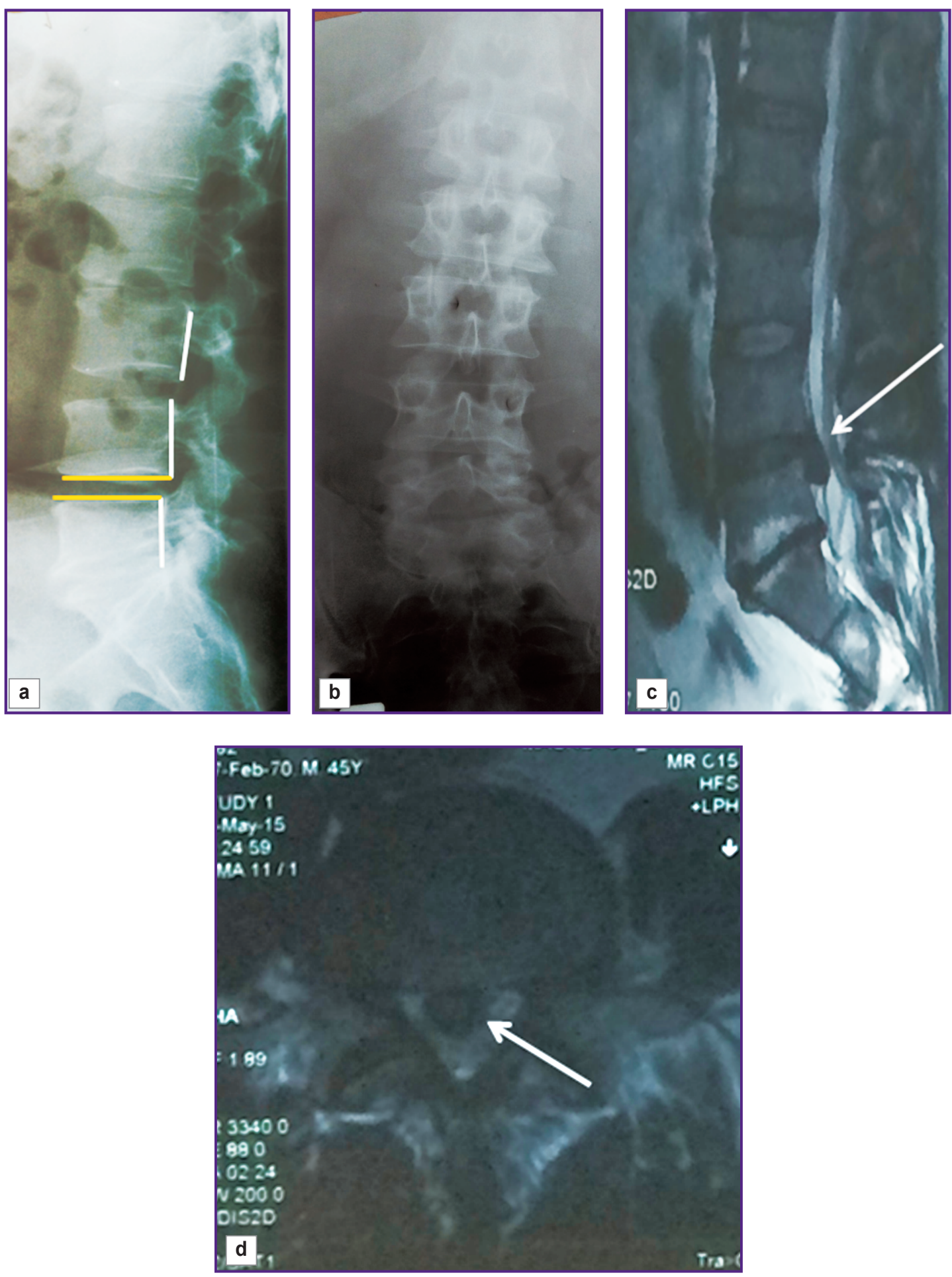

Figure 4. Patient S., aged 39, diagnosis: "Dorsopathy. Osteochondrosis of the lumbosacral spine. $L_{i v}-L_{V}$ disc herniation with the spinal canal stenosis. $L_{v}-S_{1}$ disc protrusion. $L_{i v}$ vertebra retrolisthesis. Neurogenic intermittent claudication. Right-sided L5, S1 radiculoneuritis. Right-sided lumbar ischialgia syndrome. Marked pain and muscular tonic syndrome": (a) lateral X-ray view of the lumbosacral spine before surgery $-L_{I V}-L_{V}$ interbody height loss, $L_{I V}$ vertebra retrolisthesis; (b) anteriorposterior X-ray view of the lumbosacral spine before surgery; (c) sagittal MRI of the lumbosacral spine (the arrow shows $\mathrm{L}_{\mathrm{IV}}-\mathrm{L}_{\mathrm{V}}$ disc herniation obstructing the spinal canal); (d) frontal MRI of the lumbosacral spine (the arrow shows $L_{I V}-L_{V}$ disc herniation); (e), (f) lateral and anterior-posterior X-ray view of the lumbosacral spine - recovery of the operated segment height and general lumbar lordosis, no signs of migration and instability of fixation elements have been identified; $(\mathrm{g})$ sagittal MRI of the lumbosacral spine; (h) frontal MRI of the lumbosacral spine, no data confirming compression of neural structures and signs of progressive degeneration and migration in the VMS adjacent to the surgical site have been obtained; (i) sagittal MSCT of the lumbosacral spine; (j) frontal MSCT of the lumbosacral spine, CT signs of bone-metal block formation 

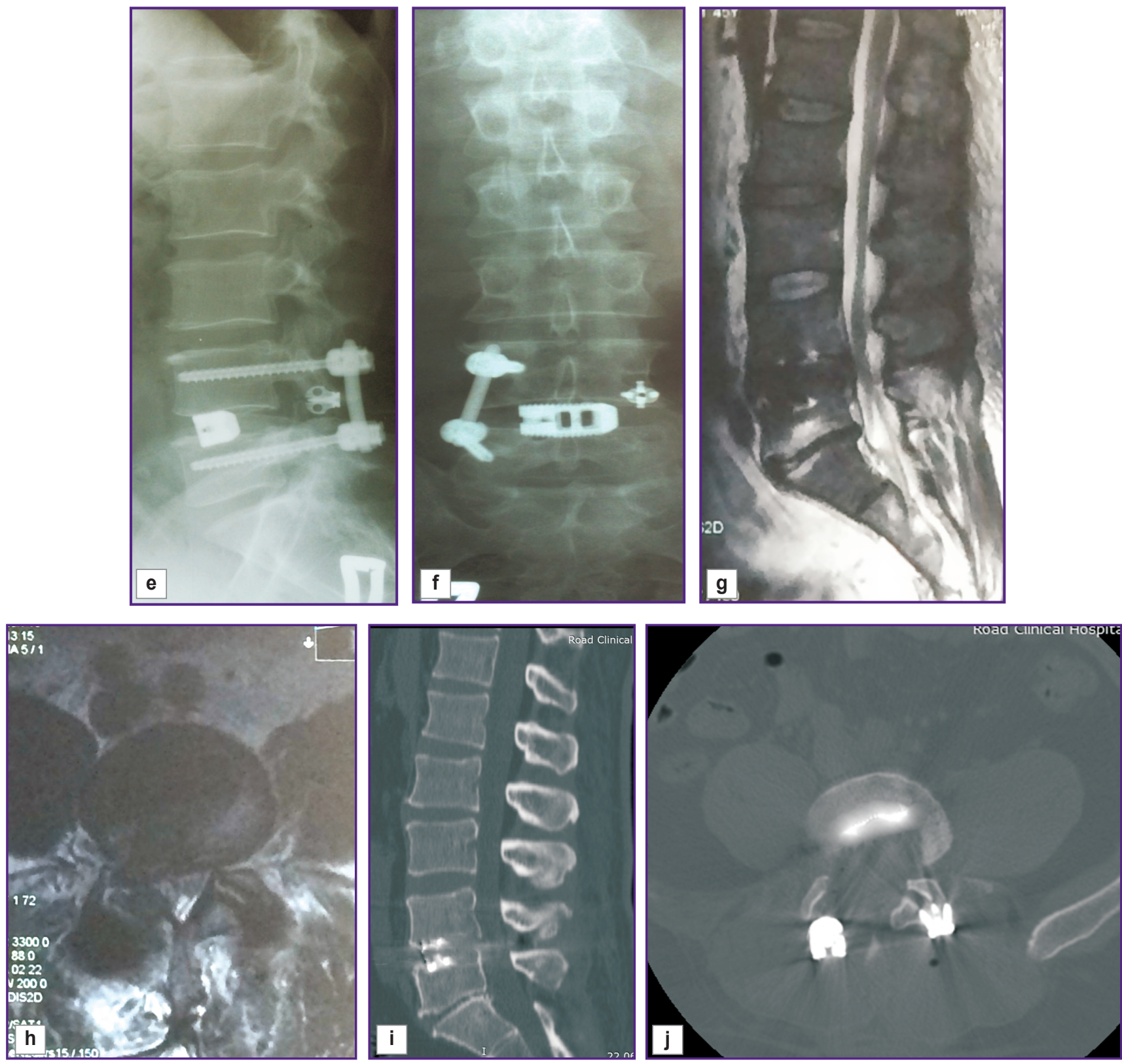

\section{Continuation Figure 4}

of patient S., aged 39, with degenerative disease of the lumbosacral spine.

Discussion. Reliable interbody bone block formation is a necessary requirement in treatment of many degenerative diseases of the lumbosacral spine [1, 8]. Interbody fusion has traditionally been performed via anterior, posterolateral and posterior access. A number of complications such as overload of posterior supporting elements and damage to neurovascular structures in anterior interbody stabilization as well as risks of durotomy and significant traction of neural structures in posterior fixation necessitated the search for new technological solutions [2, 5, 7]. The method of TLIF introduced in 1982 allowed reducing iatrogenic aggressiveness of access and development of intracanal scar-adhesion changes [20].

Further investigations intended to reduce the number of manipulations in the surgical wound contributed to the study of biomechanical efficacy of unilateral transpedicular screw fixation as less traumatic compared to bipedicular fixation [21, 22]. However, the investigations speak of less flexional - extensional and rotational stability provided by unilateral transpedicular stabilization [23, 24].

Subsequently, in order to improve clinical results of treating patients, preserving stability of the operated spinal segment, a combination of unilateral TLIF and translaminar facet fixation through the base of the 
spinous process was proposed [12]. Biomechanical and clinical trials confirmed low injury rate, relative simplicity and significantly lower risks of damaging the spinal canal content as compared to bilateral transpedicular stabilization, with fixation rigidity remaining comparable $[25,26]$.

In this investigation, we used combined dorsal stabilization by way of transforaminal interbody cage fixation with transpedicular screws on one side and Facet Wedge cage on the contralateral side. The study of biomechanical efficacy of the abovementioned implant on cadaver evidences the comparability of segment stability with transpedicular stabilization stability and biomechanical advantages over translaminar facet fixation [27].

When evaluating clinical efficacy of unilateral TLIF combined with Magerl facet fixation in treatment of patients with degenerative diseases of the lumbosacral spine, Jang and Lee [28] revealed a decrease in back pain severity after surgery from the average of 75 to $23 \mathrm{~mm}$ according to VAS, lower extremities pain from 74 to $7 \mathrm{~mm}(p<0.01)$ and improvement of the functional state from 33.1 to 7.6 according to ODI. Jiang et al. [29] point at the reduction of pain in the back from the average of 76 to $21 \mathrm{~mm}$ and lower extremities pain from 75 to $6 \mathrm{~mm}$, with disability degree according to ODI declining from 49.1 to 5.6. When evaluating stabilization efficiency and terms of fusion formation, some authors established development of reliable bone block in a bigger number of patients (more than $90 \%$ ), on average, 12 months after surgery [28-32].

Comparison between published clinical and radiographic data on interbody fusion by means of transpedicular screw fixation in combination with Magerl facet fixation obtained by different groups of authors and our findings is shown in the Table.

In this study, we obtained no statistically significant differences in clinical outcomes and terms of fusion formation compared to the data provided by the literature.

After surgery, all the patients showed statistically significant improvement of the functional state confirmed by the minimum number of ODI scores and low level of pain by VAS as well as radiographic signs of reliable interbody fusion formation in $89 \%$ of patients 12 months after surgery.

Thus, facet fixation technology using Facet Wedge implant in combination with transforaminal interbody fusion and unilateral transpedicular screw fixation in treatment of patients with degenerative diseases of the lumbosacral spine ensures reliable bone block formation and efficient stabilization of the operating segment at low intraoperative injury. Recovery of the anatomical relations in the operated vertebral motion segment contributes to safe and early activation of patients reducing the risk of intra- and postoperative

\section{Comparison between published data on interbody fusion by means of transpedicular screw fixation} in combination with Magerl facet fixation in treatment of patients with degenerative diseases of the lumbosacral spine and the findings of our investigation

\begin{tabular}{|c|c|c|c|c|c|c|c|c|}
\hline $\begin{array}{l}\text { Author, year } \\
\text { of publication }\end{array}$ & $\begin{array}{l}\text { Number } \\
\text { of patients }\end{array}$ & $\begin{array}{l}\text { Observation } \\
\text { period } \\
\text { (months) }\end{array}$ & $\begin{array}{l}\text { Blood } \\
\text { loss (ml) }\end{array}$ & $\begin{array}{l}\text { Surgery } \\
\text { duration } \\
\text { (min) }\end{array}$ & $\begin{array}{l}\text { VAS changes } \\
\text { before surgery/ } \\
\text { after surgery } \\
(0-100 \mathrm{~mm})\end{array}$ & $\begin{array}{l}\text { ODI before } \\
\text { surgeryl } \\
\text { after surgery } \\
(0-100 \mathrm{~mm})\end{array}$ & $\begin{array}{l}\text { Bone block } \\
\text { formation } \\
\text { after surgery }\end{array}$ & Complications \\
\hline $\begin{array}{l}\text { Jang and Lee, } \\
2005 \text { [28] }\end{array}$ & 23 & $19[13 ; 28]$ & 310 & 150 & $\begin{array}{l}\text { In the back: from } 75 \\
\text { to } 23 \text {; in the lower } \\
\text { limb: from } 74 \text { to } 7\end{array}$ & From 33.1 to 7.6 & $\begin{array}{l}92 \% \\
\text { in } 12 \text { months }\end{array}$ & No \\
\hline $\begin{array}{l}\text { Jiang et al., } \\
2014 \text { [29] }\end{array}$ & 50 & $17[6 ; 30]$ & 150 & 90 & $\begin{array}{l}\text { In the back: from } 76 \\
\text { to } 21 \text {; in the lower } \\
\text { limb: from } 75 \text { to } 6\end{array}$ & From 49.1 to 5.6 & $\begin{array}{l}88.6 \% \\
\text { in } 12 \text { months }\end{array}$ & $\begin{array}{l}1 \text { - damage } \\
\text { to the root } \\
\text { by the screw }\end{array}$ \\
\hline $\begin{array}{l}\text { Xu et al., } 2013 \\
{[30]}\end{array}$ & 19 & $17.1[12 ; 24]$ & 156 & 158 & - & - & $\begin{array}{l}100 \% \\
\text { in } 12 \text { months }\end{array}$ & $\begin{array}{l}1 \text { - damage } \\
\text { to dura mater }\end{array}$ \\
\hline $\begin{array}{l}\text { Mao et al., } \\
2013 \text { [31] }\end{array}$ & 16 & $16.5[12 ; 24]$ & $186 \pm 226$ & $148 \pm 75$ & - & - & $\begin{array}{l}100 \% \\
\text { in } 16 \text { months }\end{array}$ & No \\
\hline $\begin{array}{l}\text { Shao et al., } \\
2015 \text { [32] }\end{array}$ & 22 & $18[12 ; 32]$ & - & - & $\begin{array}{l}\text { From } 82.0 \pm 7.2 \\
\text { to } 31.8 \pm 0.66\end{array}$ & $\begin{array}{l}\text { From } 36.72 \pm 6.84 \\
\text { to } 4.36 \pm 1.12\end{array}$ & $\begin{array}{l}100 \% \\
\text { in } 12 \text { months }\end{array}$ & $\begin{array}{l}1-\text { damage } \\
\text { to dura mater }\end{array}$ \\
\hline $\begin{array}{l}\text { Data obtained } \\
\text { by the authors } \\
\text { of this article }\end{array}$ & 19 & $14[12 ; 16]$ & $90[65 ; 150]$ & $150[90 ; 175]$ & $\begin{array}{l}\text { In the back: from } 68 \\
{[64 ; 78] \text { to } 6[4 ; 8] ;} \\
\text { in the lower limb: } \\
\text { from } 82[78 ; 85] \\
\text { to } 3[2 ; 4]\end{array}$ & $\begin{array}{l}\text { From } 74[66 ; 78] \\
\text { to } 8[8 ; 10]\end{array}$ & $\begin{array}{l}89 \% \\
\text { in } 12 \text { months }\end{array}$ & $\begin{array}{l}1 \text { - muscular } \\
\text { hematoma } \\
\text { infection }\end{array}$ \\
\hline
\end{tabular}


complications, rapid and complete social and labor rehabilitation of patients.

Conclusion. Posterior decompression with a novel minimally invasive technology of combined dorsal fusion provides the possibility to significantly reduce pain, lower the degree of disability and perform efficient stabilization of the operated vertebral motion segment in patients with degenerative diseases of the lumbosacral spine.

Study Funding. The study was supported by the grant of the Russian Science Foundation (project 15-15-30037).

Conflicts of Interest. The authors have no conflicts of interest to disclose.

\section{References}

1. Byvaltsev V.A., Sorokovikov V.A., Kalinin A.A., Egorov A.V., Belykh E.G., Panasenkov S.Yu. Comparative analysis of the results of decompression and single-stage decompression-and-stabilizing operations at the treatment of discoradicular conflict of lumbosacral segment of spine. Byulleten' Vostochno-Sibirskogo nauchnogo tsentra Sibirskogo otdeleniya Rossiyskoy Akademii meditsinskikh nauk 2011; 4(1): 38-43.

2. Krutko A.V. Comparative analysis of posterior interbody fusion and transforaminal interbody fusion in combination with transpedicular fixation. Vestnik travmatologii $i$ ortopedii im. N.N. Priorova 2012; 1: 12-21.

3. Mobbs R.J., Phan K., Malham G., Seex K., Rao P.J. Lumbar interbody fusion: techniques, indications and comparison of interbody fusion options including PLIF, TLIF, MITLIF, OLIF/ATP, LLIF and ALIF. J Spine Surg 2015; 1(1): 2-18.

4. Asil K., Yaldiz C. Retrospective comparison of radiological and clinical outcomes of PLIF and TLIF techniques in patients who underwent lumbar spinal posterior stabilization. Medicine 2016; 95(17): e3235, https://doi.org/10.1097/ md.0000000000003235.

5. Harms J., Rolinger H. A one-stager procedure in operative treatment of spondylolistheses: dorsal tractionreposition and anterior fusion. Z Orthop Unfall 1982; 120(3): 343-347, https://doi.org/10.1055/s-2008-1051624.

6. Jin-Tao Q., Yu T., Mei W., Xu-Dong T., Tian-Jian Z., Guo-Hua S., Lei C., Yue H., Zi-Tian W., Yue Z. Comparison of MIS vs. open PLIF/TLIF with regard to clinical improvement, fusion rate, and incidence of major complication: a metaanalysis. Eur Spine J 2015; 24(5): 1058-1065, https://doi. org/10.1007/s00586-015-3890-5.

7. Goldstein C.L., Macwan K., Sundararajan K., Rampersaud Y.R. Comparative outcomes of minimally invasive surgery for posterior lumbar fusion: a systematic review. Clin Orthop Relat Res 2014; 472(6): 1727-1737, https://doi. org/10.1007/s11999-014-3465-5.

8. Byvaltsev V.A., Kalinin A.A., Belykh E.G., Sorokovikov V.A., Shepelev V.V. Optimization of segmental lumbar spine instability treatment using minimally invasive spinal fusion technique. Voprosy neirokhirurgii im. N.N. Burdenko 2015; 79(3): 45-54, https://doi.org/10.17116/ neiro201579345-54.

9. Sakeb N., Ahsan K. Comparison of the early results of transforaminal lumbar interbody fusion and posterior lumbar interbody fusion in symptomatic lumbar instability. Indian J Orthop 2013; 47(3): 255, https://doi.org/10.4103/00195413.111484 .
10. José-Antonio S.-S., Baabor-Aqueveque M., SilvaMorales F. Philosophy and concepts of modern spine surgery. Acta Neurochir Suppl 2011; 108: 23-31, https://doi. org/10.1007/978-3-211-99370-5_5.

11. Pellisé F., Hernández A., Vidal X., Minguell J., Martínez C., Villanueva C. Radiologic assessment of all unfused lumbar segments 7.5 years after instrumented posterior spinal fusion. Spine 2007; 32(5): 574-579, https://doi. org/10.1097/01.brs.0000256875.17765.e6.

12. Magerl F.P. Stabilization of the lower thoracic and lumbar spine with external skeletal fixation. Clin Orthop Relat Res 1984; (189): 125-141, https://doi.org/10.1097/00003086198410000-00014.

13. Buttermann G.R., Thorson T.M., Mullin W.J. Outcomes of posterior facet versus pedicle screw fixation of circumferential fusion: a cohort study. Eur Spine J 2013; 23(2): 347-355, https://doi.org/10.1007/s00586-013-2999-7.

14. Chin K.R., Seale J., Cumming V. Mini-open or percutaneous bilateral lumbar transfacet pedicle screw fixation. J Spinal Disord Tech 2015; 28(2): 61-65, https://doi. org/10.1097/bsd.0b013e31827fe17e.

15. Kretzer R.M., Molina C., Hu N., Umekoji H., Baaj A.A., Serhan H., Cunningham B.W. A comparative biomechanical analysis of stand alone versus facet screw and pedicle screw augmented lateral interbody arthrodesis: an in vitro human cadaveric model. Clin Spine Surg 2016; 29(7): E336-E343, https://doi.org/10.1097/bsd.0b013e3182868ef9.

16. Fujiwara A., Lim T.H., An H.S., Tanaka N., Jeon C.H., Andersson G.B., Haughton V.M. The effect of disc degeneration and facet joint osteoarthritis on the segmental flexibility of the lumbar spine. Spine 2000; 25(23): 3036-3044, https://doi.org/10.1097/00007632-200012010-00011.

17. Wiltse L.L., Spencer C.W. New uses and refinements of the paraspinal approach to the lumbar spine. Spine 1988; 13(6): 696-706, https://doi.org/10.1097/00007632-19880600000019 .

18. Byval'tsev V.A., Belykh E.G., Sorokovikov V.A., Arsent'eva N.I. The use of scales and questionnaires in vertebrology. Zhurnal nevrologii i psikhiatrii im. S.S. Korsakova 2011; 111(9-2): 51-56.

19. Madill H.M., Brintnell E.S.G., Fitzsimmons G.W., Stewin L.L., Macnab D., Casserly M.C. Work related issues in occupational therapy: your values do count. Canadian Journal of Occupational Therapy 1986; 53(1): 13-18, https://doi. org/10.1177/000841748605300102.

20. Skovrlj B., Gilligan J., Cutler H.S., Qureshi S.A. Minimally invasive procedures on the lumbar spine. World $J$ Clin Cases 2015; 3(1): 1, https://doi.org/10.12998/wjcc.v3.i1.1.

21. Xue H., Tu Y., Cai M. Comparison of unilateral versus bilateral instrumented transforaminal lumbar interbody fusion in degenerative lumbar diseases. Spine J 2012; 12(3): 209-215, https://doi.org/10.1016/j.spinee.2012.01.010.

22. Mason R., Tennekes H., Sánchez-Bayo F., Uhd Jepsen P. Immune suppression by neonicotinoid insecticides at the root of global wildlife declines. J Environ Immunol Toxicol 2014; 1(1): 3-12, https://doi.org/10.7178/jeit.1.

23. Yang $X$., Wang H., Zhao Q., Xu H., Liu P., Jin Y. A comparison of unilateral and bilateral pedicle screw fixation combined with transforaminal lumbar interbody fusion for lumbar degenerative diseases. Chin Med J (Engl) 2014; 127(20): 3592-3596.

24. Zhao J., Zhang F., Chen X., Yao Y. Posterior interbody fusion using a diagonal cage with unilateral transpedicular 
screw fixation for lumbar stenosis. J Clin Neurosci 2011; 18(3): 324-328, https://doi.org/10.1016/j.jocn.2010.06.007.

25. Sethi A., Muzumdar A.M., Ingalhalikar A., Vaidya R. Biomechanical analysis of a novel posterior construct in a transforaminal lumbar interbody fusion model an in vitro study. Spine J 2011; 11(9): 863-869, https://doi.org/10.1016/j. spinee.2011.06.015.

26. Tuli S.K., Eichler M.E., Woodard E.J. Comparison of perioperative morbidity in translaminar facet versus pedicle screw fixation. Orthopedics 2005; 28(8): 773-778.

27. Hartensuer R., Riesenbeck O., Schulze M., Gehweiler D., Raschke M.J., Pavlov P.W., Vordemvenne T. Biomechanical evaluation of the Facet Wedge: a refined technique for facet fixation. Eur Spine J 2014; 23(11): 23212329, https://doi.org/10.1007/s00586-014-3533-2.

28. Jang J.-S., Lee S.-H. Minimally invasive transforaminal lumbar interbody fusion with ipsilateral pedicle screw and contralateral facet screw fixation. J Neurosurg Spine 2005; 3(3): 218-223, https://doi.org/10.3171/spi.2005.3.3.0218.

29. Jiang X., Feng Z., Liu F., Jiang C., Cao Y. Transforaminal lumbar interbody fusion using unilateral pedicle screw fixation plus contralateral translaminar facet screw fixation in lumbar degenerative diseases. Indian J Orthop 2014; 48(4): 374, https://doi.org/10.4103/0019-5413.136240.

30. Xu J., Mao K., Wang Y., Xiao S., Li P., Mao K., Xiao B., Wang Y. A feasibility research of minimally invasive transforaminal lumbar interbody fusion using unilateral incision and hybrid internal fixation for dural-level lumbar degenerative disease. Zhongguo Xiu Fu Chong Jian Wai Ke Za Zhi 2013; 27(8): 955-959.

31. Mao K.Y., Wang Y., Xiao S.H., Zhang Y.G., Liu B.W., Wang Z., Zhang X.F., Cui G., Zhang X.S., Li P., Mao K.Z. A feasibility research of minimally invasive transforaminal lumbar interbody fusion (MIS-TLIF) using hybrid internal fixation for recurrent lumbar disc herniation. Zhonghua Wai Ke Za Zhi 2013; 51(8): 723-727.

32. Shao R.X., Luo P., Lin Y., Xu H.Z., Chi Y.L. Treatment of low lumbar degenerative disease with unilateral pedicle screw combined with contralateral percutaneous transfacet screws fixation. Zhongguo Gu Shang 2015; 28(4): 318-322. 